\title{
Disaster Risk Reduction in Myanmar
}

\author{
Beuy Joob, PhD; and Viroj Wiwanitkit, MD
}

$\mathrm{T}$ he publication on Disaster Risk Reduction in Myanmar by Smith and Chan ${ }^{1}$ concluded that although Myanmar's Action Plan for Disaster Risk Reduction addressed multiple stages of disaster development and has made progress toward national projects, it has struggled to implement community-based preparedness and response initiatives. In fact, as a tropical country in Indochina, Myanmar is located in an area that is prone to several natural disasters. Every year, there are many monsoons followed by local floods. Our experiences in disaster management emphasize that both the lack of essential public health infrastructure and unstable political and social protections contribute greatly to the mismanagement of the disasters, especially resulting in a delayed response without the benefit of otherwise effective preventive action. For example, in Thailand, despite a continued history of large flood disasters, there is still no good preparedness planning against future flooding among local health centers. ${ }^{2}$ This is just one more example of the importance of recognizing the entire disaster cycle with emphasis on prevention and preparedness, not just the response phase alone.

\author{
About the Authors \\ Sanitation 1 Medical Academic Center, Bangkok, Thailand (Joob) \\ Honorary Professor, Dr DY Patil University, Pune, India (Wiwanitkit), \\ and Visiting Professor, Hainan Medical University, Haikou, China \\ (Wiwanitkit).
}

Correspondence and reprint requests to Beuy Joob, Sanitation 1 Medical Academic Center, Bangkok, Thailand (e-mail: beuyjoob@hotmail.com).

Conflicts of Interest

None.

\section{REFERENCES}

1. Smith AD, Chan EYY. Disaster risk reduction in Myanmar: a need for focus on community preparedness and improved evaluation of initiatives. Disaster Med Public Health Prep. 2017. https://doi.org/10.1017/dmp.2017.107.

2. Rattanakanlaya K, Sukonthasarn A, Wangsrikhun S, Chanprasit C. A survey of flood disaster preparedness among hospitals in the central region of Thailand. Australas Emerg Nurs J. 2016;19(4): 191-197. 